Chibueze Callistus Duru I University of West London, UK Colin Fu I University of West London, UK

Michael Nimo I University of West London, UK

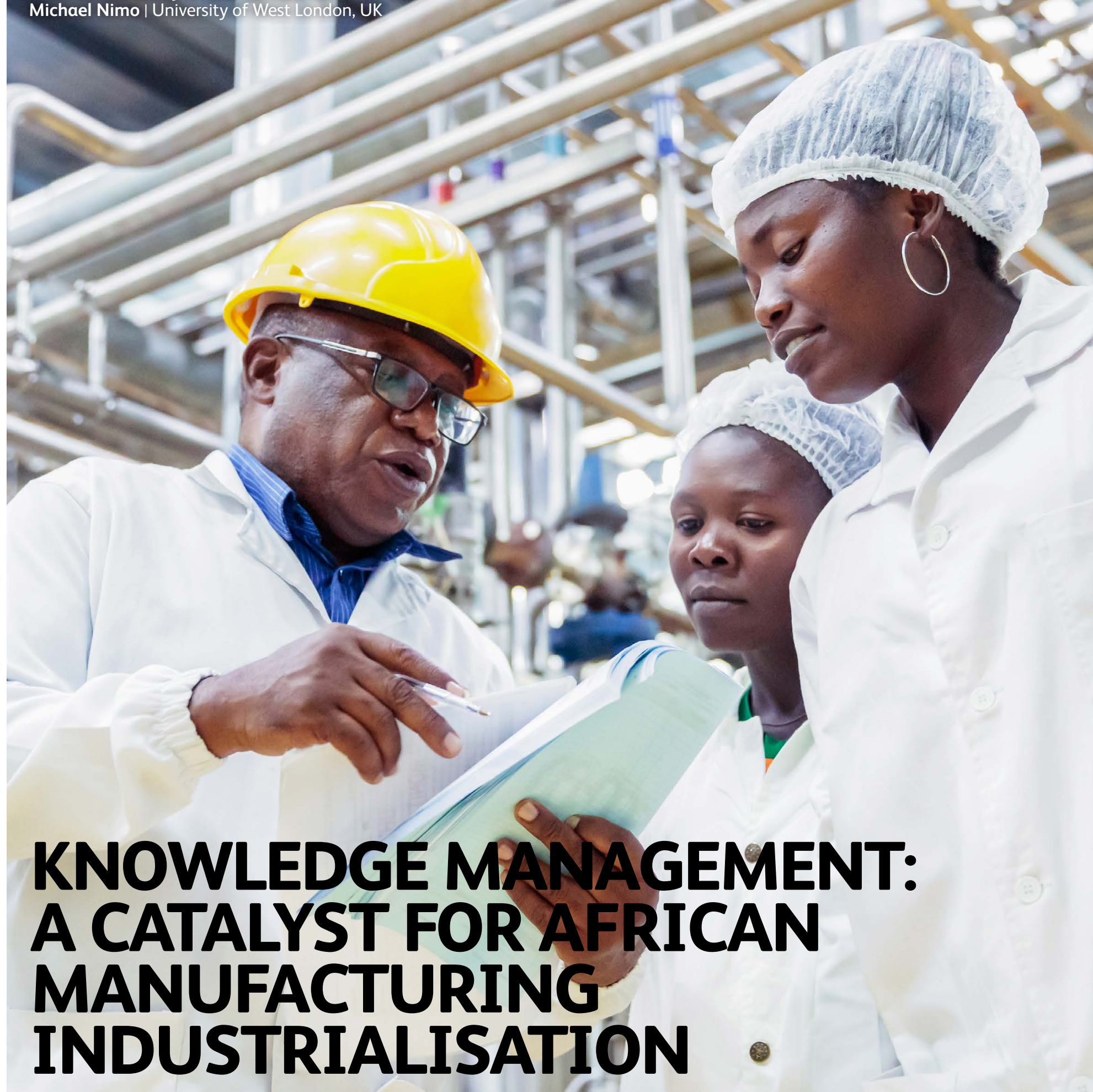

A case study of manufacturing performance drawn from four African countries 


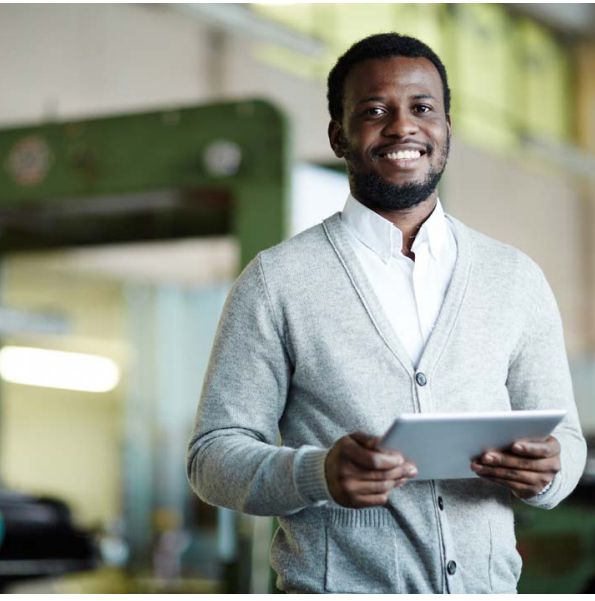

intellectual infrastructures to exploit technology changes. According to Signé and Johnson (2018), industrialisation can transform any nation. After all, it transformed countries like the United States of America, Japan, Germany, France, Italy, and the United Kingdom into the world's wealthiest nations through manufacturing. Africa too has the resources and workforce to join the industrialisation race towards the upliftment of its general society.

\section{Knowledge management in African manufacturing}

This paper defines knowledge management (KM) as 'a holistic solution incorporating a variety of perspectives, namely people, process, culture and technology perspectives, all of which carry equal weighting in managing knowledge' (Du Plessis \& Boon, 2004, p.74) in fulfilling numerous functions in the innovation realm, such as creating a conducive organisational environment that encourages innovation.

Knowledge can be implicit or explicit. Tacit knowledge plays a decisive role in innovation. Organisations build innovation capability through tacit knowledge-sharing, learning from their practices (learning-from-doing effect) so as to become more competitive. Tan and Wong (2015), in a study linkage between knowledge management and manufacturing performance, claim that tacit and explicit knowledge are quickly disseminated within an organisation via knowledge-sharing and transfer facilitated through informal and formal interactions among the organisations' stakeholders, especially its employees. Gold et al.'s (2001) theory is that KM capability is acquired through knowledge acquisition, conversion, application, and protection.

KM consists of enablers and processes (Gold et al., 2001). The application of knowledge processes in manufacturing industries depends on the factors referred to as KM enablers. According to Syed-Ikhsan and Rowland (2004), among the enablers of

$\mathrm{KM}$, human resources top the list. In a contrasting view, Gold et al. (2001) argue that infrastructure classified into technological, cultural, and structural infrastructure plays a more important role in $\mathrm{KM}$ in organisations. The absence of KM enablers affects the application of knowledge in product manufacturing and management.

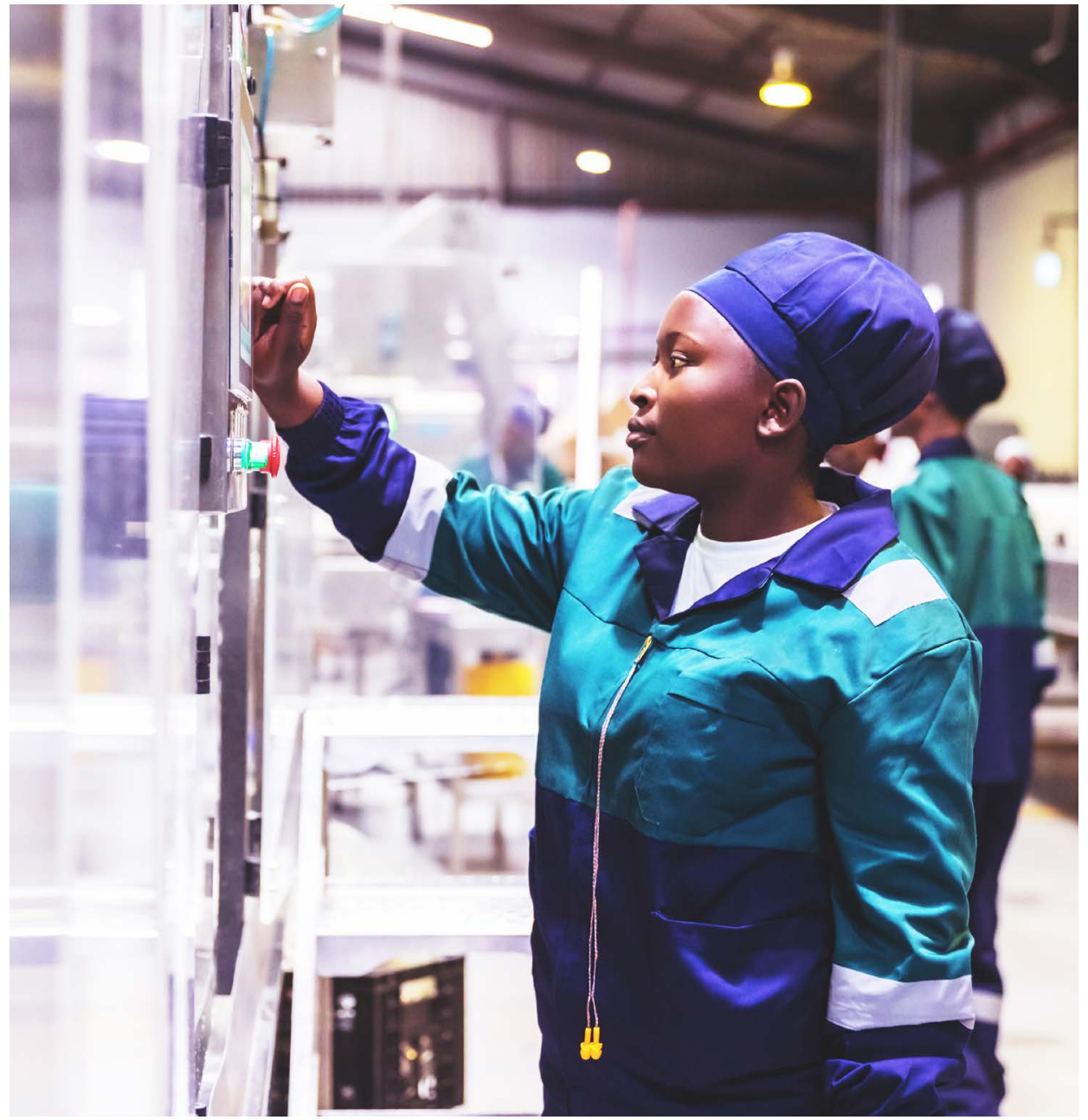

In the literature, manufacturing is defined mainly as the transformation of raw materials into goods, for example, as: "the making of products from raw materials using various processes, equipment, operations and manpower according to a detailed plan that is cost-effective to generate income through sales' (Scallan, 2003, p.3). The numerous definitions in the literature of manufacturing refer primarily to converting raw materials, including parts, into products according to certain specifications in order to satisfy customer needs. This paper argues that the definition of manufacturing as the transformation of input (raw materials) into output (goods) understates the role of data, information and knowledge. Therefore, for the purpose and scope of this paper, manufacturing is defined as:

a process that enables manufacturing

organisations to generate revenue by

combining knowledge management and

resources to purposefully transform

customer needs into tangible products and intangible services for sale at a price

that satisfies customer preferences.

Other knowledge-management activities that add value to product creation and delivery include information technology, software development, research, design, marketing, and logistics. As a result, the present paper's definition of manufacturing is more appropriate, as it covers all the operations involved in creating products and services.

This paper adopts the perspective that manufacturing ability can determine a country's wealth and prosperity, based on the existing disparity between countries with advanced manufacturing processes, known as developed countries. In contrast, those with not much manufacturing ability are called underdeveloped nations. Nations depend on manufacturing to create wealth, enabling health services, education, transport, entertainment, telecommunication and manufacturing. Therefore, a healthy manufacturing industry is vital to the well-being of a nation and its inhabitants. Moreover, industrial products form the fabric of civilisation, because a country without manufacturing capacity runs the risk of social and economic decline. 


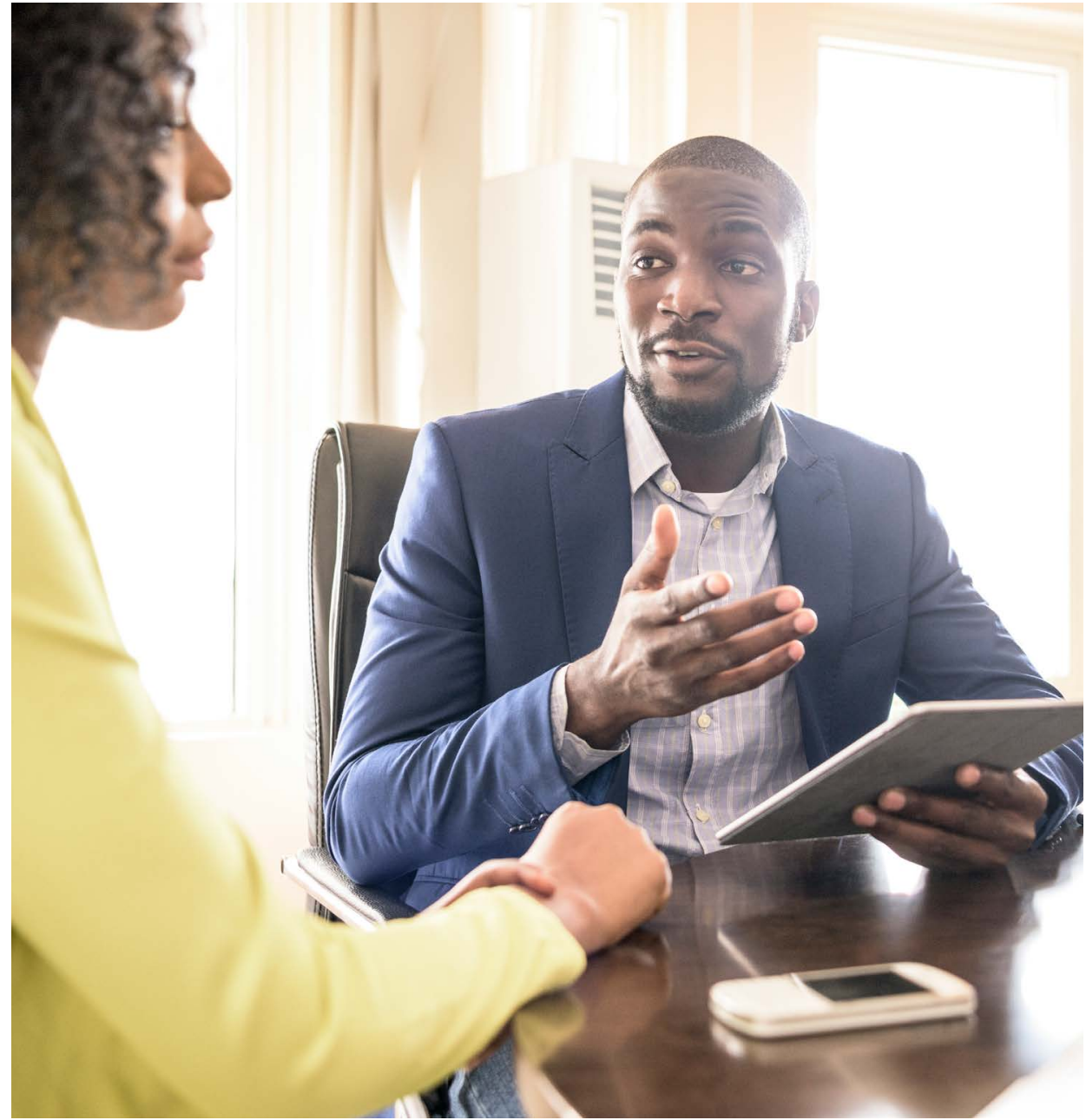

\section{Knowledge-Based Theory versus}

\section{Resource-Based Theory}

Wernerfelt (1984) considered knowledge

to be the most strategic resource of an organisation. According to this author, knowledge and competence form the foundation of organisation competitiveness and performance. Knowledge is rooted and inherent in many entities such as documents, organisational culture, policies, routines and systems (ibid.). This perception was initially promoted as the foundation of the organisation resource-based view.

Notwithstanding that this view recognised that knowledge bases enable organisations to achieve a competitive advantage, some scholars of the knowledge-based view argue that the resourcebased perspective is similar to the knowledge-based view. Explicitly, knowledge is considered as a vast resource instead of one with unique characteristics as in the resource-based view. Therefore, there is no distinction between the various types of knowledgebased capabilities. In the knowledge-based view, information technologies play a vital role in creating, improving, and accelerating large-scale intra- and inter-organisational knowledge management. 'Knowledge resources, KM processes and KM factors have significant and direct effects on manufacturing performance' (Tan \& Wong, 2015, p.814).

\section{The key drivers of the African \\ manufacturing sector}

Human resources and intellectual properties are crucial economic growth and manufacturing investment drivers according to the Global Manufacturing Competitiveness Index Survey. Organisations use their knowledge resources to pursue business objectives. As argued by Syed-Ikhsan and Rowland (2004), human capital is a crucial asset capable of generating and managing knowledge that helps enhance productivity; knowledge as capital is intrinsic in the workforce and not the organisation. Also, employee competencies determine the organisations' capability to realise competitive advantage. Therefore, human resources knowledge contributes to organisational intellectual property. The intangible factors that can hinder or promote African manufacturing productivity and affect the capability to adopt new technologies include a lack of desirable employability skills that hinder innovative production methods. Thus, exploiting intangible assets can be as productive as managing physical assets (Davenport \& Prusak, 1998). Accordingly, for African industrialisation through manufacturing, matching intangible assets with tangible physical assets can enhance performance. Therefore, both tangible and intangible assets are necessary to achieve an African manufacturing competitive advantage.

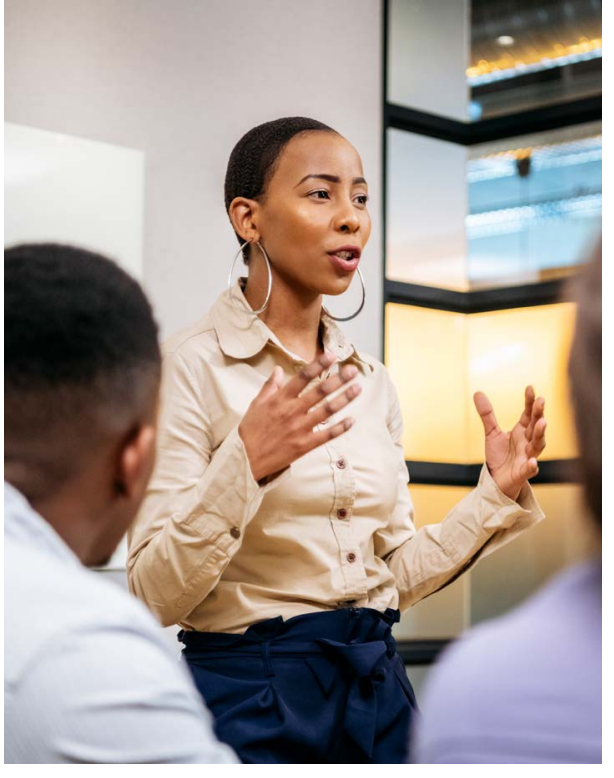

Human resources

knowledge contributes

to organisational

intellectual property. The

intangible factors that

can hinder or promote

African manufacturing

productivity and affect the

capability to adopt new

technologies include a lack

of desirable employability

skills that hinder innovative production methods

Regarding the role of workforce skills in African industrialisation, highly skilled workers can be considered the organisation's most valuable and unique assets. Imagine a specialist technician with more than twenty-five years of knowledge and experience retiring or leaving. What a significant loss to the organisation if there is no proper knowledge documentation. Effective knowledge management enables manufacturers to provide a structured and repeatable approach to identifying knowledge gaps, untapped knowledge and avoid reinventing the wheel. 
Therefore, good knowledge management of knowledge assets, linked to the organisation's physical assets, enhances manufacturing performance (Davenport \& Prusak, 1998).

In terms of organisational infrastructure and technology, Hill (1987) classified knowledge management in manufacturing strategy into two parts, structure and infrastructure. While structures refer to process and technology - the design, development and implementation of manufacturing strategy, infrastructure covers human resources policies, organisational culture, IT and quality systems. The author argues that infrastructure strengthens the structure and that organisational infrastructure and technology play an essential part in the practice of $\mathrm{KM}$ in an organisation. Today, technology-based communication systems have facilitated information searching, storing, updating, accessing, and retrieving KM infrastructures. They enable knowledge-sharing activities such as information research in the organisation. Therefore, KM infrastructures are vital in African manufacturing industrialisation for communication and collaboration in searching for a new product or for process development-knowledge. African manufacturing organisations can use innovative infrastructures to implement KM in order to coordinate production processes and collaborate with all organisation stakeholders to facilitate their business objectives. Knowledge management infrastructures enable accessible information-sharing through formal and informal employees interactions that enhance knowledge creation and application.

Generally, the assumption is that knowledge acquisition provides problem-solving solutions for manufacturing. Nonetheless, knowledge acquisition without a sound understanding of how to implement it leads to implementation failure. African manufacturing organisations can gain more knowledge by accumulating facts and data from past problem-solving experiences, projects, training, product research and development. The acquisition of experience through learning boosts an individual's capability to make decisions and take action. Since knowledge is the combination of information and expertise, African manufacturing organisations can form a culture of using knowledge management to provide their workforce with the ability to utilise processes previously adopted to solve similar problems. Thus, African manufacturers can effectively create, share, apply, and protect knowledge to overcome environmental uncertainties by improving manufacturing performance.

Knowledge enhances organisational performance. Since individual knowledge evolves continuously, organisational knowledge evolves too, because of the prominent role of human capacity and environmental circumstances, specifically culture. African manufacturers must identify the vital factors that enhance knowledge creation and sharing in internal and external collaborations among organisational stakeholders in order to meet customer needs. The process of knowledge sharing plays an essential role in converting personal or group knowledge into organisational knowledge. The
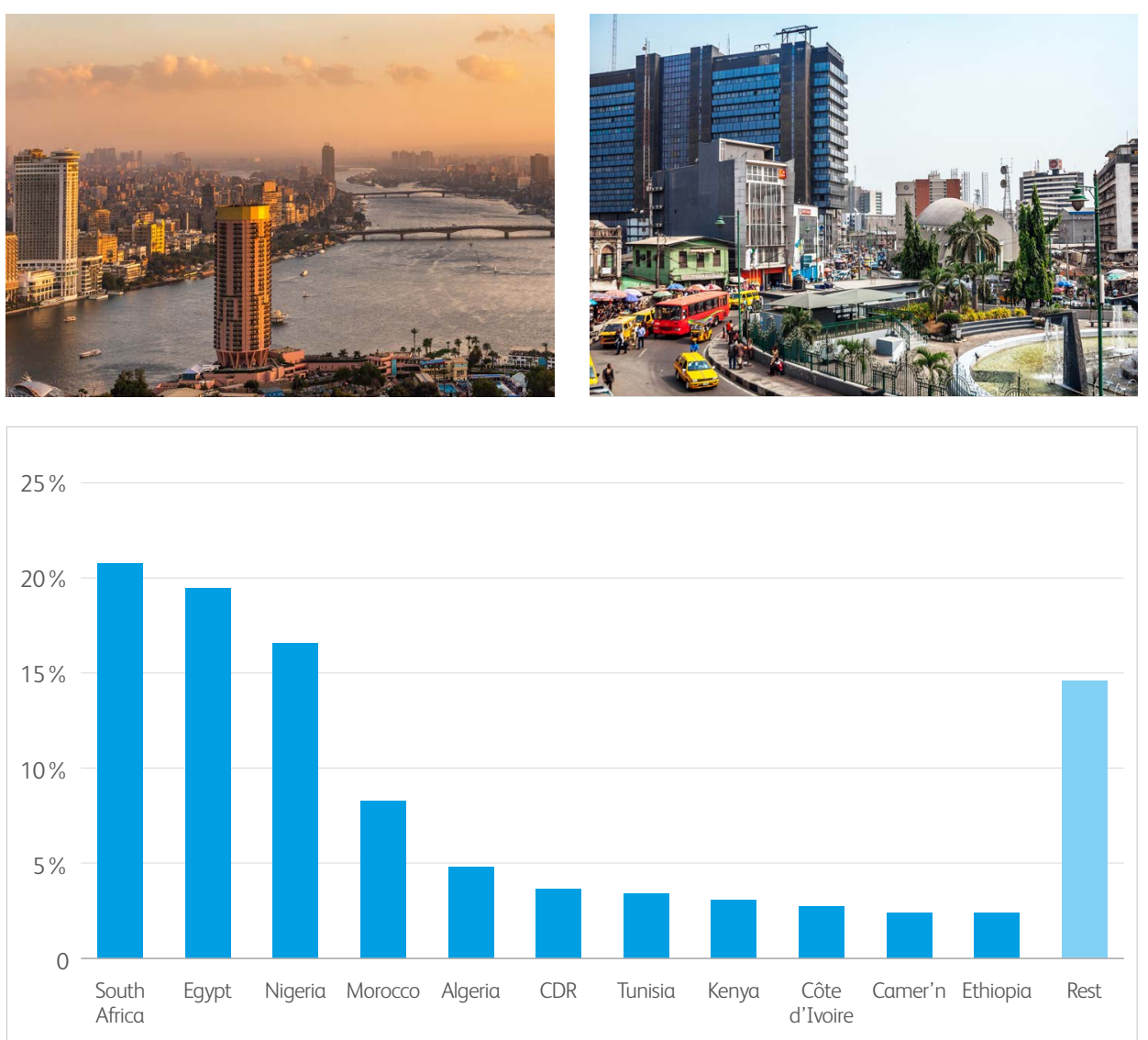

FIGURE 1 The importance of an African single market (World Development Indicators, 2017)

African manufacturing industry's knowledge-creation capacity can depend on its workforces' employability skills, conducive workplace, and prevailing innovation environment.

Many foreign direct investments (FDI) are concentrated in a few countries. Figure 1 shows that most African manufacturing production companies are in South Africa, Egypt, Nigeria and Morocco. Some African governments are making significant strides in promoting regional clusters and special zones (SEZ) to attract more foreign investments (FDI) that will positively impact on technology transfer that is essential for productive transformation. McKinsey Global Institute (2016) has reported that the manufacturing sector would be driven by increasing networks between African countries and the rest of the world, with its rapidly growing consumer markets in the coming years.

Signé and Johnson (2018) point out that Africa needs achievable and reliable single market policies that are vital for the continent's progress and industrialisation. Africa is still moving too slowly towards a single market, even though the African Continental Free Trade Agreement was unveiled in Kigali, Rwanda, in March 2018. However, Africa's quest for a single market through the Organisation of African Union (OAU) dates back to 1963 . There is certainly a need for
African manufacturers mustidentify the vital factors that enhance knowledge creation and sharing in internal and external collaborations among organisational stakeholders in order to meet customer needs 
a functional African Continental Free Trade Area (AfCFTA) like the European Community. This could offer the African continent a key industrialisation strategy, a single customs union for the free movement of goods and services, including people and capital. The AfCFTA, compared to the European Union or the USA, would have the capacity to foster a competitive manufacturing sector and boost African economic development by creating a continental free market, an African common market (Signé \& Johnson, 2018). If successfully implemented, the free-trade area would outsize any existing trade area, including countries with 55 members and a population covering more than 1.2 billion, estimated to triple by 2050 and entail over $\$ 4$ trillion in combined consumer and business spending.

\section{Methodological considerations}

This paper presents a case study of manufacturing performance drawn from four culturally different African countries considered the continent's economic hubs where most African manufacturing production companies are located. This study used secondary data analysis, that is already compiled, gathered, organised and published literature, in order to establish the sum of existing knowledge on the African manufacturing sector's organisational performance. In searching the web, the keywords used are manufacturing, knowledge management, African single market, and endogenous growth. It emerged that Nigeria, Kenya, Morocco, and South Africa are among the four countries that can become the continent's economic hubs (Signé \& Johnson, 2018). In finding detailed information on the African manufacturing sector, the web-search was country-specific, for example, the Nigerian manufacturing sector and the manufacturing sector in Morocco or Kenya.

Based on the manufacturing value-added for top producers in Africa 2017, South Africa, Morocco, Kenya and Nigeria, emerged as future African business hubs (Signé \& Johnson, 2018). Kenya is considered a business hub, because it is among East Africa's most economically innovative and technologically advanced countries and scored $4 \%$ as one of Africa's easy places to obtain credit for business investments. According to the Kenyan government's 10-point policy goal, the percentage of manufacturing contribution to the GDP will increase by $15 \%$ and create about 300,000 job opportunities in 2022. Based on Kenya's present annual GDP growth rate of $5.7 \%$, it is possible to double its manufacturing sector's output to meet the government's target. The government's plan to achieve the set objectives involves implementing the manufacturing development by reforming existing policies to align closely with Kenya's Industrial Transformation Programme (KITP), Vision 2030. Kenya ranked at fourth position in Africa after the Seychelles, Ghana, and Zambia regarding competitive advantage on the international market, based on the World Economic Forum judgment.

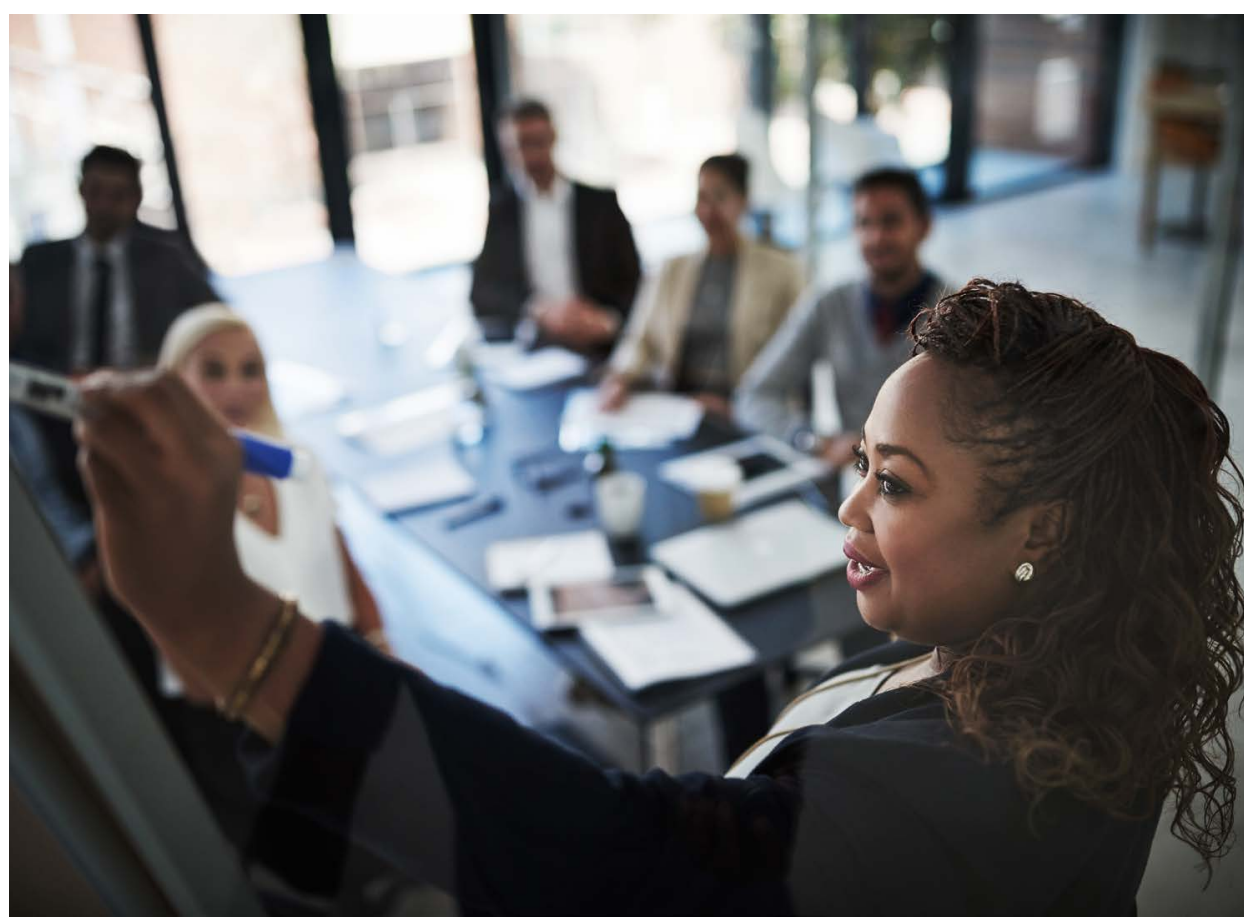

Global Innovation Index 2020 Ranks

\begin{tabular}{|c|c|c|c|c|}
\hline & Nigeria & Morocco & Kenya & South Africa \\
\hline Corruption Perception Index 2020 & 149 & 86 & 124 & 69 \\
\hline Market Sophistication & 102 & 95 & 57 & 15 \\
\hline Credit & 87 & 95 & 20 & 107 \\
\hline Ease of getting credit & 14 & 101 & 4 & 9 \\
\hline Human Capital and Research & $(121)$ & 81 & 110 & 70 \\
\hline Expenditure on Education ( $\%$ of GDP) & $\mathrm{n} / \mathrm{a}$ & 34 & 29 & 13 \\
\hline Innovation Linkages & 86 & 117 & 31 & 43 \\
\hline Infrastructure & 124 & 71 & 114 & 79 \\
\hline Political and Operational Stability & 128 & 76 & 104 & 92 \\
\hline Research and Development (R\&D) & $(121)$ & 71 & 77 & 42 \\
\hline University / Industry Research Collaborations & 122 & 113 & 36 & 30 \\
\hline Business Environment & 109 & 59 & 60 & 75 \\
\hline Creative Goods and Services & (78) & 105 & 69 & 92 \\
\hline Knowledge Creation & 108 & 71 & 67 & 52 \\
\hline Knowledge Impact & 109 & 51 & 90 & 92 \\
\hline Knowledge Diffusion & 121 & 51 & 65 & 78 \\
\hline
\end{tabular}

TABLE 1 Comparing the African economic hubs (Global Innovation Index, 2020) 


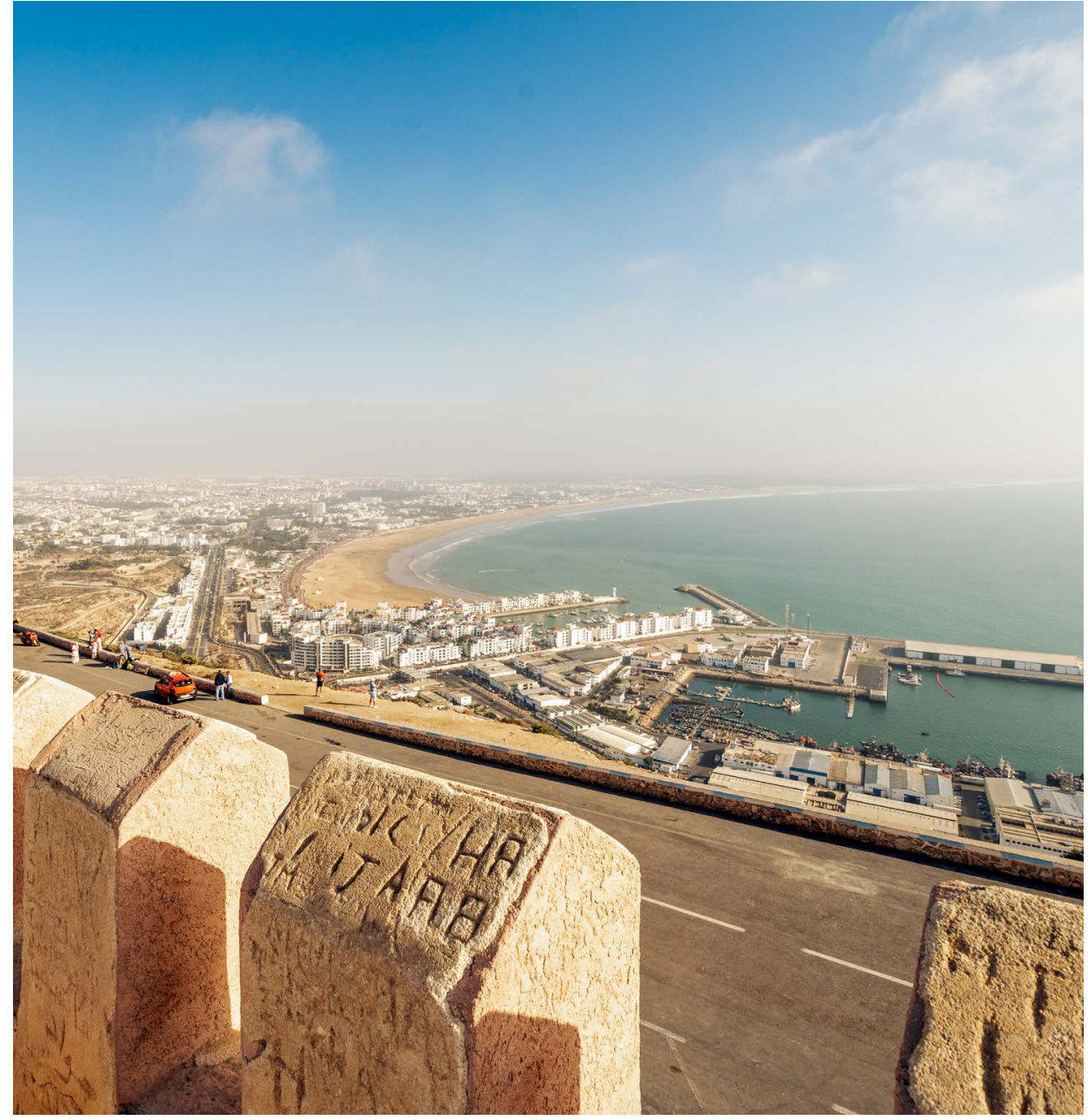

The principal factor

contributing to Morocco's consideration as one of the African economic hubs is its capacity to benefit from its geographical location between the Atlantic Ocean and the Mediterranean Sea, precisely its proximity to Europe via Gibraltar and Spain
Nigeria has secured the most influential and the largest economy in West Africa due to the abundance of oil and gas. It has the most significant petroleum import and export industry in Africa. Thus, it is among the most prominent economic hubs in the western part of Africa, but still lags in innovation, political and operational stability, business environment, university/industry research collaboration, knowledge creation, impact, and diffusion, based on the Global Innovation Index. Despite the government's various economic policies, the manufacturing sector continues to make an insignificant contribution to GDP. The Nigerian government has evidently failed to understand the crucial factors that make industrialisation happen, such as a stable political environment, infrastructures like a constant electrical power supply, good communication system and sustainable economic development policies. Although macroeconomic variables and economic policies are considered vital determinants of a nation's economic performance, this paper maintains that the most critical aspect is implementation. The sector's underperformance is also attributable to 'poor economic policies, and ethnic division' (Sachs \& Warner,1997, p.336), including inadequate infrastructures such as electricity supply and economic-related factors like high exchange rates, inflation, and a high interest rate.
South Africa is among the African economic hubs due to its booming mineral-energy complex and innovative manufacturing sector. The country's mining sector, such as platinum, gold, diamond and coal, including its most advanced agricultural sector in Africa, have contributed massive wealth to the economy. Adopting innovative production processing methods has enabled the South African agro manufacturing sector to create profitable business opportunities for local and international markets, attracting investors worldwide. Based on the Global Innovation Index, South Africa is a growing knowledge economy hub. Much attention is focused on education, ICT technology, and e-commerce with higher market sophistication than other African countries, but with a low score in credit for business investments. In 2017/18 World Economic Forum (WEF), South Africa ranked 61 out of 137 countries in which to do business. The WEF reported that among the problematic factors for doing business in South Africa is corruption. The South African manufacturing sectors contribute about $11 \%$ of the country's employment and $13 \%$ of GDP.

The principal factor contributing to Morocco's consideration as one of the African economic hubs is its capacity to benefit from its geographical location between the Atlantic Ocean and the Mediterranean Sea, precisely its proximity to Europe via Gibraltar and Spain. Morocco is one of the major players in African affairs, ranked fifth as African's largest economy by GDP and securing first position as the most competitive economy in North Africa, according to the African Competitiveness Report 2014-2015 and 53rd in the World Bank's Doing Business 2020 benchmark business environment report. Morocco has the busiest and largest port on the Mediterranean and Africa, with a capacity to handle about 9 million containers, 700,000 trucks and 1 million vehicles a year, and ranked 18th globally. The country has become the regional hub for shipping, logistics, assembly, production, and sales for North, West and Sub-Saharan Africa. 


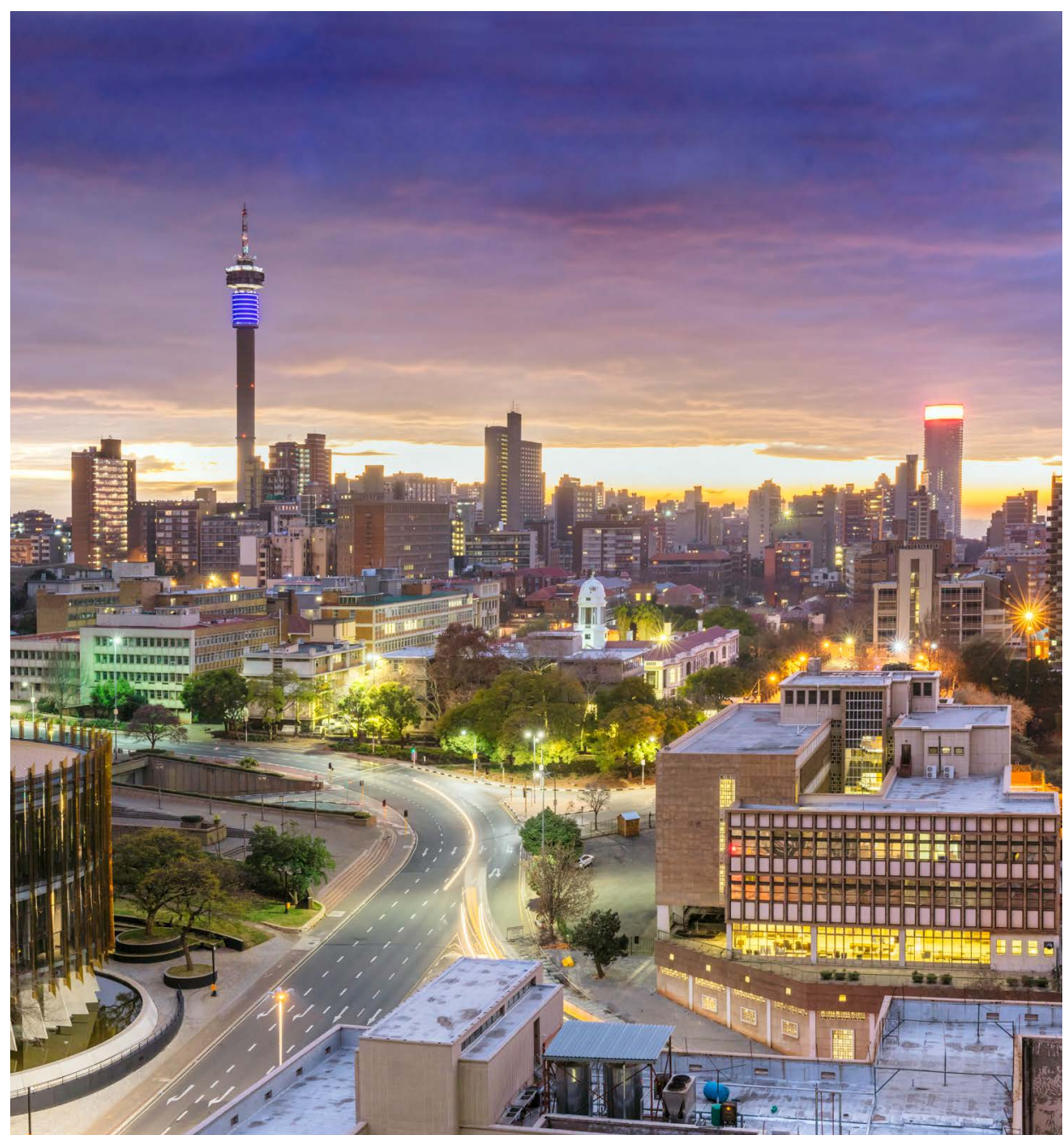

\section{Conclusion}

Regardless of the negative factors like disruptive technology, COVID-19 pandemic, political instability, and more besides, this paper concludes that African countries can still use knowledge management to achieve industrialisation through manufacturing. Even though manufacturing has existed for centuries, it can still be considered the cornerstone of industrialisation, because it so positively influences economic growth. Finally, leaders and policymakers must create an environment that effectively encourages employees and teams to fully exploit knowledge at work and in the marketplace.

\section{Contribution to knowledge}

This paper contributes to existing knowledge from an African cultural perspective on the importance of knowledge creation and application in manufacturing for African industrialisation through an endogenous strategy. By adopting and embracing knowledge management, African countries can create a coherent and collective endogenous growth strategy that integrates basic development principles with local characteristics to improve socio-economic growth. 'Endogenous growth is economic growth at a rate determined by internal forces to the economic system, particularly those governing the opportunities and incentives to create technological knowledge' (Okereke \& Agupusi, 2015, p.31).

\section{References}

Davenport, T. H. \& Prusak, L. (1998) Working knowledge: How organisations manage what they know. Boston, MA: Harvard Business School Press.

Du Plessis, M. \& Boon, J.A. (2004) The role of knowledge management in eBusiness and customer relationship management: South African case study findings. International Journal of Information Management, 24(1): 73-86 Gaviria-Marin, M., Merigó, J. M. \& Baier-Fuentes, H. (2019) Knowledge management: a global examination based on bibliometric analysis. Technological Forecasting and Social Change, 140: 194-220

Global Innovation Index (2020) Economic Trend Analysis । Economic Review 2021 I GII 2021. Retrieved from https://www. globalinnovationindex.org/analysis-economy

Gold, A.H., Malhotra, A. \& Segars, A.H. (2001) Knowledge Journal of Management Information Systems, 18(1): 185-214 Hill, T. J. (1987) Teaching manufacturing strategy. International Journal of Operations \& Production Management, 6(3): 10-20

Lillrank, P. (2020) Declining Society and Systems Productivity. In Handbook of Systems Sciences, edited by G. Metcalf, K. Kijima \& H. Deguchi, 1-18. Singapore: Springer.

McKinsey Global Institute (2016) Lions on the move II: Realising the potential of Africa's economies. Retrieved from https://www.mckinsey.com/ /media/McKinsey/Featured \% 20 Insights/Middle \% 20East \% 20and \% 20Africa/Realizing \% 20 the \% 20potential \% 20of \% 20Africas \% 20economies/ MGI-Lions-on-the-Move-2-Executive-summary-September2016v2.ashx

Meagher, K. (2016) The scramble for Africans: Demography, globalisation, and Africa's informal labour markets. Journal of Development Studies, 52(4): 483-497

Naudé, W. (2018) Brilliant technologies and brave entrepreneurs. Journal of International Affairs, 72(1): 143-158 Newfarmer, R., Page, J. \& Tarp, F. (2019) Industries without smokestacks: Industrialisation in Africa reconsidered. Oxford: Oxford University Press.

Okereke, C. \& Agupusi, P. (2015) Homegrown Development in Africa: Reality or Illusion? New York: Routledge.

Sachs, J.D. \& Warner, A.M. (1997) Sources of slow growth in African economies. Journal of African economies, 6(3): 335-376 Scallan, P. (2003) Process Planning. Oxford: ButterworthHeinemann.

Signé, L. \& Johnson C. (2018) The Potential of Manufacturing and Industrialisation in Africa. New York: The Brookings Institution.

Syed-Ikhsan, S.O.S. \& Rowland, F. (2004) Knowledge management in a public organisation: a study on the relationship between organisational elements and the performance of knowledge transfer. Journal of knowledge management, 8(2): 95-111

Tan, L.P. \& Wong, K.Y. (2015) Linkage between knowledge management and manufacturing performance: a structural equation modelling approach. Journal of Knowledge Management, 19(4): 814-835

Timmer, M.P. Erumban, A.A., Los, B., Stehrer, R. \& de Vries, G.J. (2014) Slicing up global value chain. Journal of Economic Perspectives, 28(2): 99-118

Wernerfelt, B. (1984) The resource-based view of the firm: Ten years after. Strategic Management Journal, 16(3): 174-74

World Bank (2017) World Development Report 2017: Global Value Chain: Measuring and Analyzing the Impact of GVCs on Economic Development. Washington: World Bank Group. to achieve effective post-COVID-19 homegrown knowledge management, manufacturers in countries like Nigeria, Ghana, Morocco, South Africa, and other African countries should enhance their expertise and capacity to discern and make decisions based on knowledge management. Understanding the nature of ability enables the transformation of meaning from facts to knowing customer needs and the acquisition of implementation capacity to satisfy customers adequately. Therefore, African manufacturers have to start forming a frugal mindset, looking around at their environment and developing technologies to solve local customers' problems. However, there is also nothing wrong with importing knowledge and innovation, but a lack of adequate knowledge for using and maintaining them effectively is potentially disastrous.

\section{About the authors}

Chibueze Callistus Duru is a PhD student in the Claude Littner Business School at the University of West London. Dr Colin Fu is a Senior Lecturer in Business and Management at the University of West London. Dr Michael Nimo is a Senior Lecturer in Economics and International Business at the University of West London.

\section{Keywords}

Manufacturing, knowledge management, African single market, Nigeria, endogenous growth

This is an open access article under the terms of the Creative Commons Attribution License (https://creativecommons org/ licenses/by/4.0/), which permits use, distribution and reproduction in any medium, provided the original work is properly cited. (c) The Authors. New Vistas Published by University of West London.

The design, art direction and photography elements remain the intellectual property of the copyright holders and are not included in the Creative Commons Attribution license applied to the rest of this work. Photographs \& illustrations ( ) Jebens Design Ltd (Jebens Design - www.jebensdesign.co.uk). Cover Photography (Claire Williams Photography - www.clairewilliamsphotography.co.uk). 